\title{
A Brief Analysis of the Buddhist Implication and Connotation of the "Mat Lion Dance" in Meizhou
}

\author{
浅谈梅州 “席狮舞” 中的审美意蕴及内涵 \\ Shijie Liu ${ }^{1}$ and Yuelong Zhang ${ }^{2}$ \\ ${ }^{1}$ Shenzhen Huafeng Culture Media Co., China \\ ${ }^{2}$ Department of Dance, Faculty of Dance, Shenzhen University, China
}

\begin{abstract}
The "Mat Lion Dance" is one of the unique events of the "XiangHua" (which means fragrant flowers in Chinese) Buddhism ritual in Meizhou Hakka, Guangdong, China. From the perspective of aesthetics, the current study will analyze and discuss its cultural background and history as well as its artistic expression and intrinsic value. The article will emphasize three aspects: the relationship between the Hakka and Buddhist cultures; the implications of the performance and process of the Mat Lion Dance; and the function of praying, uniting the clan, and blessing of the Mat Lion Dance. The aim of the article is to deepen public understanding of the Mat Lion Dance, a precious intangible cultural heritage, and enable it to be better protected and inherited.
\end{abstract}

Keywords: Kejia people, Meizhou, Buddhist ceremony, Mat Lion Dance

\section{摘要}

“席狮舞” 为广东梅州客家 “香花” 佛事中独有的项目之一，根据现有资料，“席狮 舞" 在50年代初之前一直在民间发展传承，作为一项客家佛教仪式流传于民间，并于 2008年被列入第二批国家级非物质文化遗产保护名录。由于梅州特殊的地理人文环 境，以及当地客家人民文化与佛教文化的互相交融，形成了独特的“香花”佛仪，而“ 席狮舞" 作为 “香花” 佛事中的一部分，同样具有它独特且不可替代的作用。本文正是 通过了解分析 “席狮舞” 的舞蹈形态与过程，进而探究 “香花” 佛事中 “席狮舞” 的动 作与过程所代表的意境与内在涵义，以使得 “席狮舞” 这一宝贵文化获得认知，让这一 非物质文化遗产得到有效的保护与传承

关键词 : 梅州客家，佛仪，席狮舞

\section{Introduction}

Rituals originate from people's spiritual beliefs, formed through the impact of their surroundings, mental demands, the development of culture as well as the structure of knowledge, and are developed and changed along with people's social and working lives. Therefore, the historical background, cultural traditions, and the demands of people that have shaped the unique ritual dance of the Mat Lion Dance are investigated to understand its connections with the Hakka people (Li \& Wang, 2014). It is believed that apart from the beauty of the dance, the Mat Lion Dance is also representative of the Meizhou Hakka folk culture, which also has its special connotation in the "XiangHua” Buddhism ritual. 


\section{The "Mat Lion Dance" in the "XiangHua" Buddhist ritual}

The "Mat Lion Dance" is a traditional folk dance exclusive to the Hakka people of Meizhou, Guangdong, China. It is a recreational activity that is conducted by the Hakkas in Meizhou as part of the traditional life ritual, "XiangHua" Buddhism ceremony, in which monks and the nuns intersperse among the Buddha (He, 2017). As a ceremony for mourning the deceased, the "XiangHua" Buddhism ceremony is the carrier for both Buddhist and Meizhou Hakka cultures. As the "Mat Lion Dance" is taken as one part of the "XiangHua" Buddhism ceremony, it is naturally regarded as the product of the blending and mingling of Buddhist and Hakka cultures and greatly fascinates the Hakka people in Meizhou. Thus, there is a deep and profound relationship between Buddhist and Hakka cultures.

\subsection{The origin and relation of the Buddhist ceremony and Hakka culture}

The original relation between Buddhist and Hakka cultures is rooted in ancient times, intertwined and influenced by each other through time. According to historical data and archeological evidence, Buddhist culture was introduced into the Meizhou Hakka area around 4,000 years ago, in the Northern and Southern Dynasties. Therefore, the accumulation of historical and cultural significance over thousands of years has allowed the "Mat Lion Dance" in Meizhou to become a ceremonial dance.

On a cognitive level, Buddhism advocates yin-yang samsara (in Chinese philosophy, cycle all the time in the circle of time and space) and kindness. Therefore, Buddhism has been widely recognized and accepted in the Hakka area of Meizhou, and its doctrine has been practiced by a large amount of the population from different classes. Through history, Buddhism in Hakka culture in Meizhou has developed from the impact of the law of righteousness and the Buddhism of the orthodox elites to the emergence of the secular Buddhism, which holds a different doctrine from elite Buddhism, and, eventually, the disappearance of elite Buddhism. The quintessence of elite Buddhist culture is retained as a unique ritual in the XiangHua ceremony in Meizhou. The local Hakka society and culture have also been greatly influenced by the introduction of Buddhism, and therefore, its elements can be found tightly integrated within the lives of the Hakka people of Meizhou (Li, 2005). Being a unique Buddhist ritual of Meizhou, "XiangHua" formed from the interaction of Buddhist and Meizhou Hakka cultures and evolved from generation to generation, eventually becoming a unique Buddhist death ceremony.

\subsection{The "Mat Lion Dance" in Meizhou}

The "Mat Lion Dance" is a Buddhist ritual performed by the Hakka people in Meizhou during the Buddhist death ceremony "XiangHua." In ancient Meizhou, the majority of the locals lived in low and narrow houses by the mountains or rivers and are rather far from each other. Therefore, to leave enough time for mourners to travel, a funeral usually takes a few days, while the guests and host stay up all night. Based on these special geographical and humanistic factors, the "Mat Lion Dance" in the "XiangHua" 
ritual was greatly desired by the Meizhou Hakkas because, in this way, their tiredness and sadness while attending the ceremony would be eased. The name of the ritual "XiangHua" originally referred to the "incense" and "flower" that were commonly used in the Buddhist ritual. Because both "incense" and "flower" were believed to serve a function of communicating with gods, the meaning of "XiangHua" was sublimed to imply respect for the Buddhist god (Li \& Wang, 2014). This basic function is expressed via the name of the ritual_ "XiangHua." As an important procedure of the ritual, the "Mat Lion Dance” in Hakka is an emblematic representation of this function.

The word "XiangHua" represents not only a Buddhist funeral ceremony with unique Meizhou characteristics, but also the performers of the "XiangHua” ritual, who are from the secular Buddhist temples, as opposed to the elite Buddhist temples, as well as their daily lives. Therefore, “XiangHua” became a general term for the Buddhism funeral ritual, professionalized religious personnel, and secularization of temple life in Meizhou. Under the impact of Hakka and Buddhist cultures, the "Mat Lion Dance" has become a unique Buddhist ritual dance that represents Hakka filial piety and Buddhist doctrine and has been widely and actively practiced by the Hakka people as a life ritual for praying for the deceased. It is hence becoming the gist lifeline of the Hakka people at home and abroad, with the goal of maintaining their cultural roots.

\section{The artistic presentation forms of the "Lion Dance"}

The Lion has been portrayed as a very auspicious creature that represses evil since ancient times in China. Therefore, it is frequently shown as the main character in many folk dances, which can bring people not only auspicious significance but also happiness, enlivening the atmosphere. The "Mat Lion Dance" is one of the unique forms of dance that imitates the lion, amalgamating not only music and dance but also acrobatics and drama. One complete “Mat Lion Dance” involves rhythmic music, a humorous plot, and an exquisite performance from the actor. Following the music, actors change their performance from intense and powerful to smoothing and gentle. The delicate timing of visual, sound, and emotional displays can adjust the atmosphere of the funeral. The "Mat Lion Dance" is outstanding for its unique feature of using a straw mat as a prop for imitating the lion. Its humor is delivered by the actor who sometimes performs like a real lion and sometimes not. The humor is controlled intricately by the actors, relaxing the audience but not causing them to burst into laughter. Although the props used in the "Mat Lion Dance" are very simple, the performance is delivered with rich and varied acting skills, and its form of artistic presentation is rather unique.

\subsection{The performance skill of taking straw mat as the lion and focusing on its intrinsic features}

The "Mat Lion Dance" is a typical prop dance and is sometimes known as "playing lion" in the Hakka area in Meizhou. The use of props is a common performing technique, which enables a dancer or choreographer to imitate the appearance of animals. For example, the "Lion Dance," a traditional Chinese prop dance, is performed by wearing the head of a lion on the head. There are two different lion dance genres in China, the "South Lion" 
and the "North Lion.” Both aim to represent the power and momentum of the lion and enable the audience to recognize the performing image-the lion—and distinguish its facial expressions. The "Mat Lion Dance" uniquely uses the straw mat as a costume, in which the actors imitate the way lions walk and jump, serving as the major event of the "XiangHua" ritual. The performance is conducted in a way similar to the "South Lion" genre in that the audience may sometimes feel the performer is an authentic lion but sometimes not during the dance. This is because the props used in the performance are not visually like lions, but the dance closely resembles the gestures of a lion. The "Mat Lion Dance" incorporates these unique features, which makes the performance vivid and lifelike without its external appearance resembling a lion. The original patterns of action in the "Mat Lion Dance" were created by the "XiangHua" Buddhist monks and nuns in Meizhou (figure 1, figure 2). Therefore, in folk practice, the "Mat Lion Dance" is also performed by them and spread among their followers (He, 2016).

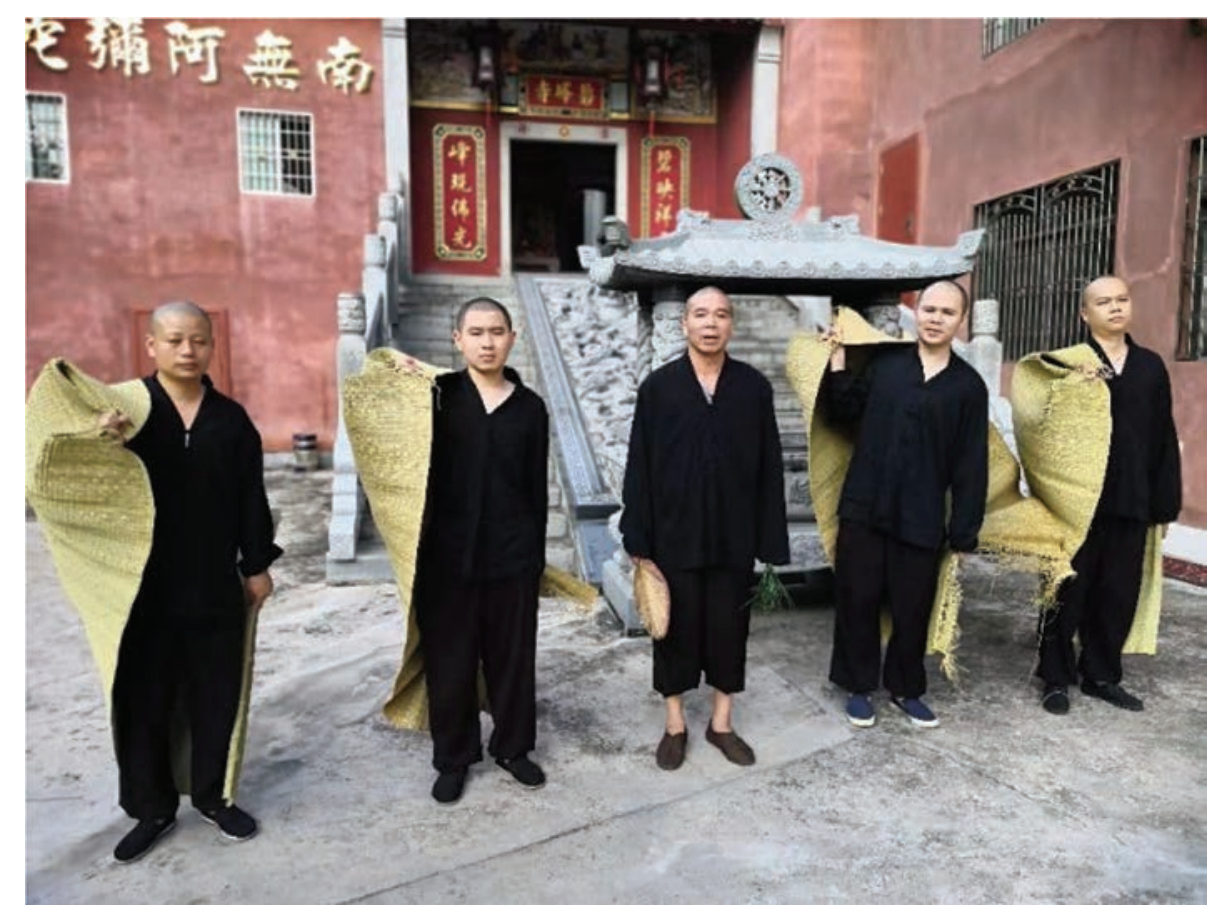

FIGURE 1 | Buddhist monks in Bifeng Temple in Meizhou, Guangdong, who inherit the “Mat Lion Dance” performance. December 15, 2015.

In contrast to general prop dances, the "Mat Lion Dance" does not always demand an extreme likeness of the image or the realistic or replication of the image. Rather, it emphasizes the vividness of the actions to deliver a lifelike performance. In the "Mat Lion Dance" of the "XiangHua" Buddha ritual, this performance technique is in line with the concept of "freehand" brushwork in traditional Chinese painting: both pursue the likeness of the intrinsic features, the spirit of the object, rather than the complete 


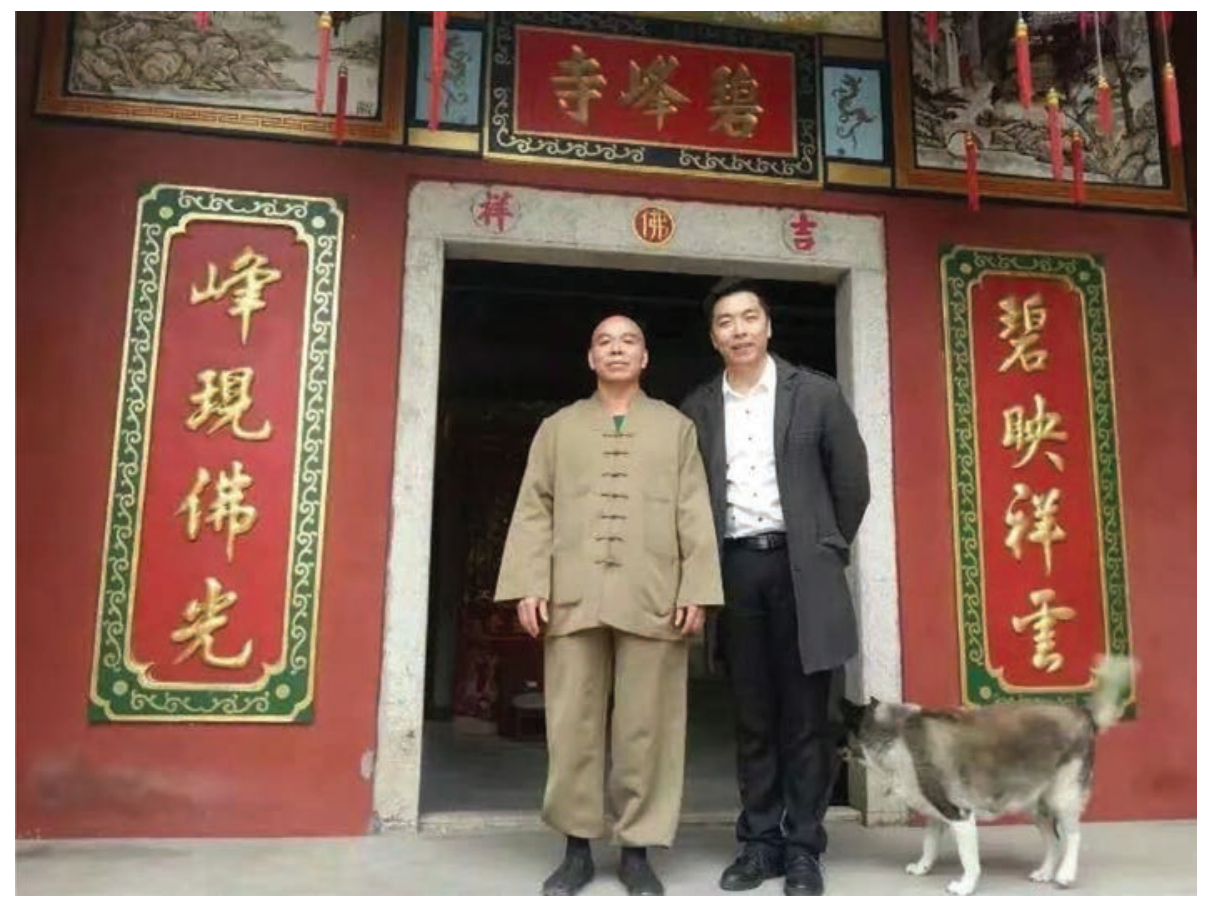

FIGURE 2 | The first author (right) with the leading Buddhist, Baohua Shi (left), who was designated as an official troupe leader, tasked with preserving this piece of Hakka culture and passing it to his students. December 15, 2015.

realism of its image. This makes the "Mat Lion Dance" stand out from other dances. "Freehand" is defined in contrast to "reality," the artist tends to ignore the external verisimilitude of the artistic image and focus on its inner spiritual essence. "Freehand" originated from Chinese brushwork and gained popularity during the Northern Song Dynasty. This artistic style requires deep embodiment of meaning in the image, so that the "image" would have an ideographic function or communicate implications to its audience. The emergence of "freehand brushwork" was a milestone in the history of Chinese art that represented a shift of aesthetic focus from objectivity to subjectivity. The delivery of the Hakka "Mat Lion Dance" aims more to set and control the atmosphere of the ceremony than to please the audience. It also shows how a monk or nun is able to apply the "free hand" style by using the prop-a "straw mat"- to imitate both the intrinsic and extrinsic beauty of lions. During the performance, the performer drapes the mat on their body to imitate the lion's body. The performer rolls one end of the mat with their right hand to represent a "head" and pulls the other end with their left hand to form a "tail." In brief, this use of "freehand" style in the prop dance uses the mat to represent lions, imitating its intrinsic features while ignoring similarities in appearance. By being able to demonstrate the spiritual features of the lion through well-practiced movements despite not having a lifelike appearance, the "Lion Dance" absolutely shows a rather high aesthetic interest and charm in Hakka Buddhist religious activities. 


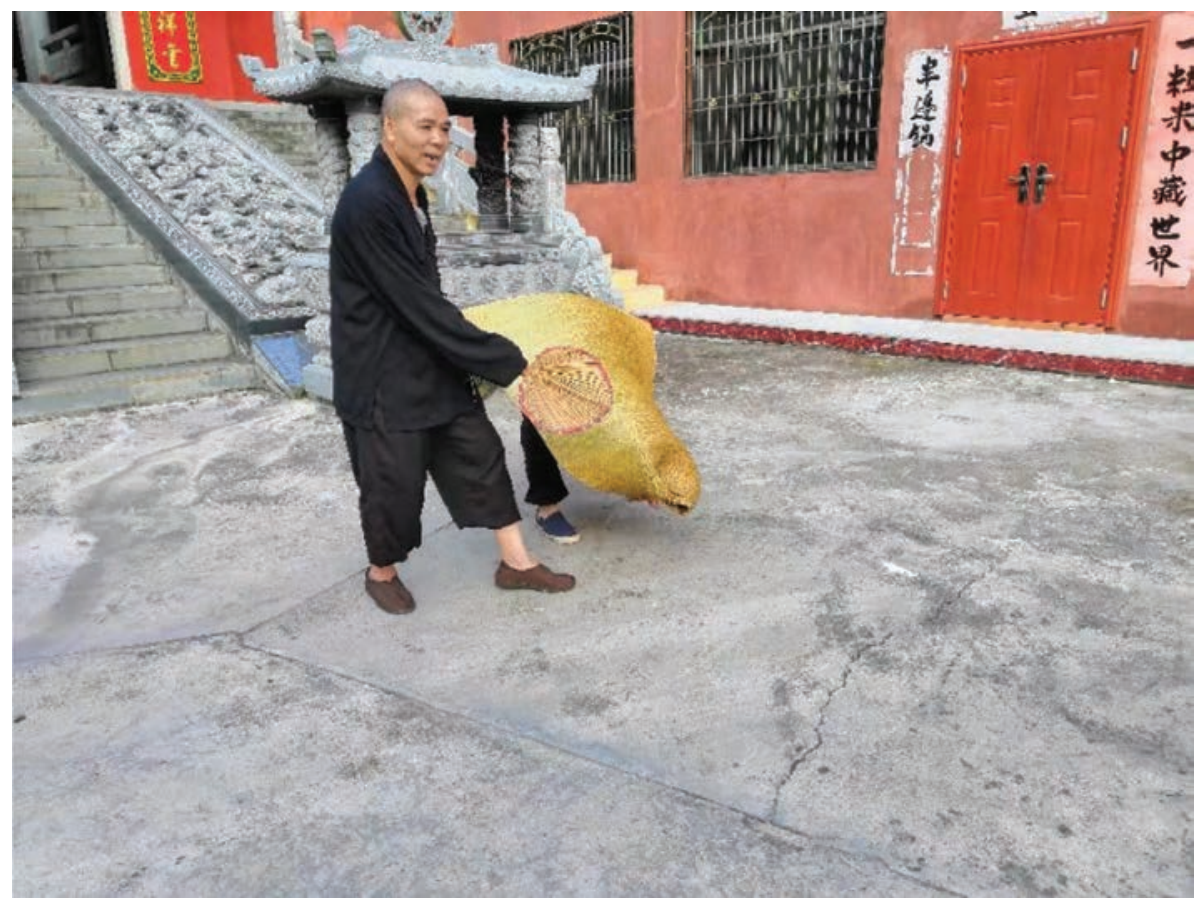

FIGURE 3 | Introducing the lion. December 15, 2015.

\subsection{The amusing and humorous features of movement}

Compared to traditional lion dances that emphasize the powerful and vigorous features of the lion, the "Mat Lion Dance" presents its beauty of dexterity and lightness, which makes it an intelligential lion (Cai, 2010). This 20-minute performance also involves a man tricking the lion with a cattail leaf fan in one hand and a purslane (also called longevity grass in China) in another. The "lion" and the man perform together through the set processes of the performance, including introducing the lion (figure 3), luring the lion, playing with the lion, planting the purslane, stealing the purslane, hiding the purslane, fighting for the purslane (figure 4), tricking the lion, and leading the lion to leave the scene. Interestingly, the performance is sometimes improvisational, subject to the mood of the dancers as well as the surrounding atmosphere. For example, when the "lion" is being lazy, the lion-tricker may choose to improvise by urinating in the water bowl and passing it to the "lion" to drink. These improvised little jokes are made to amuse the audiences.

The "Mat Lion Dance" is accompanied by gongs, drums, and cymbals for better understanding of the context and switching of story plots through use of audial cues. With one straw mat, the performer imitates the different postures and actions of the lion, greatly relying on the coordination between the right hand, left hand, and the body. The right hand of the performer represents the head of the lion, it twiddles flexibly to show the movement of lion's mouth; the right hand and the body of the performer together show the action of the lion by squatting, striding, jumping, and leaping. In this way, the lion's head can twist flexibly and agilely, and the lion's body can stretch 
and contract freely. These actions emphasize the vigorousness and anima of the lion, making it intelligential.
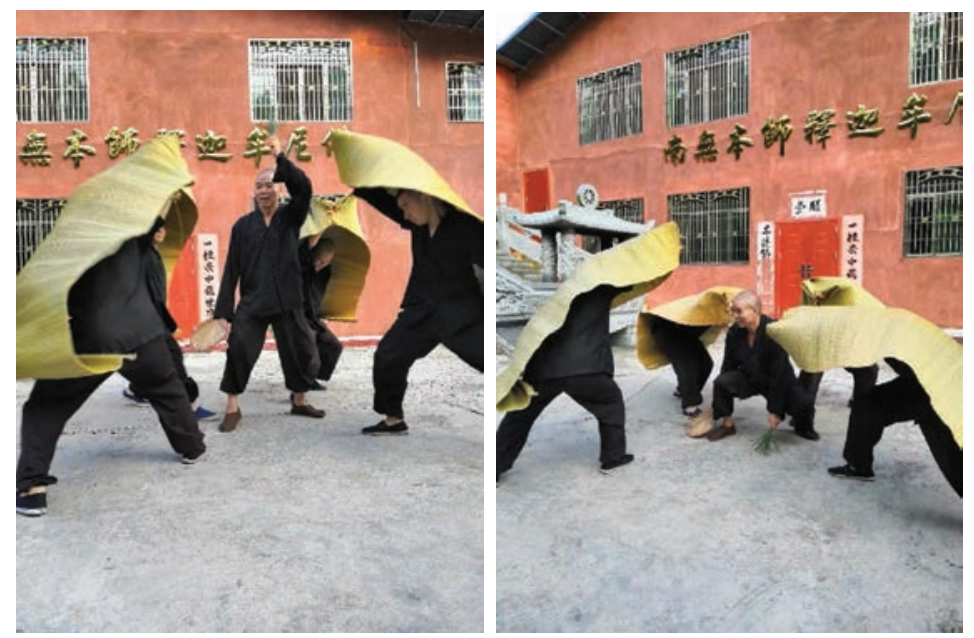

FIGURE 4 | Four "lions" are fighting for the purslane. December 15, 2015.

The flexibility of the "lion" enables it to interact with the lion-tricker in an amusing and funny funny way (figure 5). The lion dancer is able to create different movements such as shaking the head, stretching the neck, bowing, sleeping, and laying down, while the lion-tricker can retaliate by waving the fan, jumping around, and stepping back and forth to tease the lion (Cai, 2013). For example, when performing the sleeping lion, the lion-tricker cleans the lion's ears, catch the fleas, flaps the fan at the lion, while the lion shakes its head in a relaxing and humorous way. Alternatively, when the lion is stealing the purslane and fighting for the purslane, its actions are smart and lithe. The cooperation between the lion and the lion-tricker makes the dance amusing to the audience.

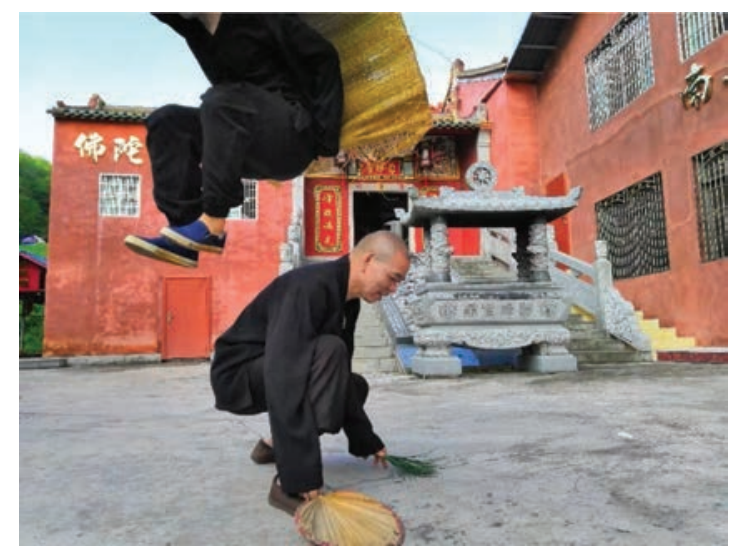

FIGURE 5 | The "lion" is jumping over the "lion-tricker" flexibly. December 15, 2015. 


\subsection{Optimism within traditional mourning ritual}

“XiangHua” is a symbol for sympathy and kindness. The "XiangHua” Buddhist ritual encourages people to continue life with the memory of the deceased, who has passed away physically but is remembered by his or her living family members. Therefore, for the relatives and friends of the deceased, it is not merely a funeral ceremony but an event representing the adjusting of emotion and the reconnection to society and community. This unique ceremony also shows the diligence, modesty, and tradition of the Hakka people. The "Mat Lion Dance," as an important event in the "XiangHua" ceremony, is loved by the local people because it represents their intrinsic characters and beliefs.

In the culture of the Meizhou Hakka people, the lion is a totem for fortune and peace and serves to exorcise evil spirits. Although the instruments used in the "Mat Lion Dance"-gongs, drums, cymbals, and Hakka big drums-are simple, the emotions they are able to deliver are rich and positive. By mourning the deceased and praying for the living via the "Mat Lion Dance" in the "XiangHua" ceremony, the Hakka people can be comforted from the sadness and hence find a spiritual sustenance.

Despite its function of mourning the dead and exorcising the evil spirits, the "Mat Lion Dance" is not as gloomy and sad as general funeral ceremonies, but it is solemn and serious. In this way, the atmosphere of the funeral can be adjusted, those who come for condolence would feel better while spending days and nights in the ceremony. Through the "Mat Lion Dance," people express their sorrow in a positive way (Li, 2011). This special practice of mourning reflects the optimistic, cheerful, and openminded philosophy and personality of the Hakka people in Meizhou. In brief, the unique intrinsic features of the "Mat Lion Dance"-modesty, diligence, and positivity-are formed by the characteristics of both the Hakka and Buddhist ritual cultures as well as the nature of the lion dance.

\section{The connotation and value of the "Mat Lion Dance"}

In traditional Chinese culture, predominantly influenced by the culture of the Han people, lions are believed to be a spiritual mascot for dispelling evil and bringing good fortune. As one of the descendants of the Han, the Hakka people in Meizhou have a cluster of complicated beliefs. Despite this, people from this clan believe that the lion can protect them and their relatives from danger and bring people auspiciousness and good fortune. The Lion Dance is regarded as a manifestation of the lion, and hence, the Hakka people embrace the "Mat Lion Dance" as a typical expression of their folk culture as well as their spiritual support. Moreover, the "Mat Lion Dance" is a traditional folk sacrifice dance that represents an interaction and blend of Hakka and Buddhist cultures. The "Lion Dance" is a ritual of "XiangHua" Buddhist ceremony in Meizhou Hakka, which has been playing a special role in folk funeral custom. Due to the cultural significance of the ceremony, it has played a significant role in the spread of Buddhism, the etiquette of life, and the evolution of the lion dance. 


\subsection{Condoling the bereaved}

People seek for spiritual sustenance from traditional rituals, through which they learn and express complicated emotions from their hearts. For the Hakka people, the "XiangHua" Buddhism ceremony is their unique way of mourning the dead and cherishing the memory of the past (Ren, 2016). The "Mat Lion Dance” plays an irreplaceable role in the "XiangHua" ceremony, as its simple and unadorned way of performance caters to the tradition of the Hakka people in Meizhou, and is the epitome of their inherited virtue of filial piety. The Hakka people always emphasize the importance of filial piety by mourning the dead via the rituals in the "XiangHua" ceremony. Through the simple music and skillful performance, people can express their grief and sorrow, seek comfort and inner peace, and prevent them from being depressed. Therefore, to spread and emphasize this virtue of filial piety, the Hakka families, regardless of financial situation, hold the "XiangHua" Buddhist funeral ceremony when a family member passes away to show respect to the deceased.

\subsection{Uniting the clansmen}

In the "XiangHua” Buddhism ceremony, the "Mat Lion Dance” also serves a function of improving the relationship between the hosts and their relatives as well as their neighbors. Because people lived far away from each other in ancient Meizhou, it takes a long time to hold the "XiangHua" funeral ceremony. Once the elder in the family passes away, other family members would immediately contact monks or nuns to chant the scripture and host the "XiangHua" Buddha ceremony. Afterwards, they need to take several days to publish the obituary and send out invitations to the relatives and friends of the family. Therefore, in most cases, the ritual would last several days and nights without any suspension. During the funeral, the Hakka people in Meizhou desire liveliness, and a deserted atmosphere is seen as a sign of unpopularity. Therefore, all friends and relatives are invited to attend. Because of the long duration of the ceremony, the guests would easily feel bored and the monks and nuns would be too tired if the only event in the ceremony is reading the scripture. Therefore, it involves some performances like the "Mat Lion Dance" and the "Cymbals Flower" to regulate the atmosphere of the ceremony, depending on the local geographical and humanistic environment. In particular, the "Mat Lion Dance" would not only adjust the atmosphere by its humorous and vivid performance but also delivers an attitude of optimism to the audience, encouraging them to treasure their lives (Cai, 2013). Therefore, the "Mat Lion Dance” is very popular and greatly welcomed by the Hakka people in Meizhou, as it helps them to ease the fatigue of the ritual and their inner sorrow.

The "Mat Lion Dance" involves simple music and sublime dance, aims to relieve people's sorrow, and is liked by the local Hakka people. Therefore, after an extended period of ritual rites, the whole family would get together to watch the performance not only to alleviate and relieve their grief for the dead but also to improve their sense of belonging and affection. In the most prosperous periods of Hakka history, anyone who was to mourn the dead would ask for such a performance, during which their neighbors and passersby were attracted to the ritual field to watch the ceremony, with large crowds 
being a common sight. Although death is unavoidable for everyone, this sort of Buddhist ritual in Meizhou enhanced the interactions among the neighborhoods and families, and the relationship and emotion between the relatives of the clan were better united.

\subsection{Praying for good luck}

Dance is an art of body language and has a very long history. It emerged from ancient rituals and sacrificial activities and therefore bears a very strong mystical quality. As a way of sacrifice, prayer, and emotional expression, dances are frequently associated with witchcraft and religious rites. Similarly, the "Mat Lion Dance" emerged to satisfy the needs of religious rituals and scarifications because the unsophisticated Hakka people in Meizhou are a clan of faith. In the traditional etiquette of the "XiangHua" ceremony, the "Mat Lion Dance" embodies the Hakka people’s will to dance for God to protect themselves and other creatures of the earth. Followers of Buddhism will perform dances to please the gods, and hence, the dance acts as a form of praying. All of these actions contribute to the goal of praying for the living. The Hakka people in Meizhou believe that lions in the "Mat Lion Dance" can exorcise the evil spirits and bring health and fortune to them. Therefore, during the ritual, the Hakka people are also willing to pray for blessings and to pray for misfortune not to descend upon them. The people there want to please the gods through the "Mat Lion Dance," hoping that the gods can bless the living and bring them good luck and health.

\section{Summary}

The "Mat Lion Dance" is more than a dance and a ritual for mourning the deceased. For the Hakka people in Meizhou, it is a representation of their culture, spiritual beliefs, and their cognition of self and the world. During the "Mat Lion Dance," they mourn the deceased, pray for the living, show their simple and unsophisticated character, and expressed their desire for peace. By analyzing and exploring the aesthetic connotation and concept of the Hakka "Mat Lion Dance" in Meizhou, our understanding of Hakka culture is deepened and our ability to appreciate ritual dances is improved. It would also lead to a better protection of this valuable cultural heritage for further exploration.

\section{About the Authors}

Shijie Liu 刘世杰 received his undergraduate degree from the Dancing Department in Shenzhen University in July 2018. He is currently working in Shenzhen Huafeng Culture Media Co., Ltd. His research interests are choreography and dance education.

Email: 401423265@qq.com

Yuelong Zhang 张月龙 is a vice professor on choreography and Chinese folk dance, and also work as the vice director of the Department of Dancing in Shenzhen University. He is also a supervisor for many postgraduate students. His research areas are choreography and dance education. He also led the project "The study of the Lingnan inherited dance culture and featured dancing education model under the key competencies onset" in 
2017, which was the higher education reform programme on education research in Guangdong.

Email: 47268265@qq.com

\section{References}

Cai, X. (2013). Analysis of the aesthetic characteristics of Hakka fragrant flower Buddhist dance in Meizhou. Journal of Xinghai Conservatory of Music, 2013(2), 54-55.

Cai, X. (2010). Comparative study of "Lion Dance” between Jiangxi and Meizhou. Journal of Jiaying University, 2010(7), 10-15.

He, Y. (2017). Research of the stage creation of lion dance in Meizhou. Guangzhou, Guangzhou University.

He, Y. (2016). The evolution of Meizhou's Lion Dance Theater under the intangible cultural heritage. The Yellow River's Voice, 2016(15), 121-122.

Li, G. (2011). A brief introduction of the functions of lion dance in south of the Five Ridges. Sports Journal, 2011(2), 129-133.

Li, G. (2005). Hakka "fragrant flower" in Meizhou research. Guangzhou, Huacheng Publishing Press.

Li C., \& Wang, K. (2014). Meizhou Hakka Buddhism fragrant flower music research. Beijing, Religious Culture Press.

Pursueand Inherit: The Mat Lion Dance in Bifeng Temple. Retrived July 20, 2017, from https://v.youku. $\mathrm{com} / \mathrm{v}$ sshow/id_XODE2MzY0MzI0.html?spm=a2h0k.11417342.soresults.dtitle.

Ren, Y. (2016). The cultural connotation and function of "fragrant flower Buddhist dance" in the perspective of dance anthropology. Chinese culture forum, 2016(8), 151-156.

Zhang, Y. (2017). A contemporary visual interpretation of the traditional folk dance "lions" in Meizhoutaking the original dance "summer fun" as an example, Guangzhou, Xinghai Conservatory of Music. 